\title{
Perceptions of the Podiatric Medicine Profession A Survey of Medical Students in Philadelphia, Pennsylvania
}

\author{
Samantha A. Miner, DPM* \\ Tracey C. Vlahovic, DPM, FFPM, FCPS (Glasg)†
}

\begin{abstract}
Background: Medical students (MSs) in allopathic and osteopathic medical programs may not be adequately exposed to the role of podiatric physicians and surgeons in health care. We explored perceptions of the specialty field of podiatric medicine from the perspective of MSs in the Philadelphia, Pennsylvania, area.

Methods: In this cross-sectional survey study, responses regarding podiatric education and scope of practice were collected via a 16-question, self-reported, anonymous online survey distributed to MSs at one osteopathic and three allopathic medical schools in the Philadelphia area. Inferences and conclusions were drawn from the percentages of respondents. Statistical analyses for school of attendance, year of study, and physician relative subgroups were performed.
\end{abstract}

Results: The 129 survey responses obtained revealed misunderstandings regarding podiatric education and training. Only $45.7 \%$ correctly answered that podiatric medical students do not take the United States Medical Licensing Examination. The results also showed the perception of podiatry in a positive light, with approximately $80 \%$ of respondents agreeing that the term doctor is applicable when referring to a podiatrist. Respondents with a physician relative were more likely to rate podiatry's role in health care higher on a scale from 0 (inessential) to 5 (equivalent to MDs/DOs) than those without a physician relative.

Conclusions: The results of this preliminary survey were generally positive and optimistic while also identifying some misconceptions regarding MS perceptions of podiatric medical training and scope of practice. Further studies are needed to evaluate perceptions of podiatry from the perspective of other members of the health-care team to improve interprofessional relations and understanding. (J Am Podiatr Med Assoc 110(5): 1-10, 2020)

As podiatric physicians and physicians-in-training, we interact daily with specialties such as primary care, vascular medicine, dermatology, infectious disease, and others. Just as we are aware of the roles that these physicians play in the health field through class instruction and/or training rotations, it is our hope that our peers have a similar understanding of podiatric medicine's role in order to provide the best care for a patient.

Studies have shown that interdisciplinary collaboration is often necessary for the effective treat-

*Temple University School of Podiatric Medicine, Philadelphia, PA. Dr. Miner is now with Mount Auburn Hospital, Cambridge, MA.

$\dagger$ Department of Podiatric Medicine, J. Stanley and Pearl Landau Faculty Fellow, Department of Microbiology, Temple University School of Medicine, Philadelphia, PA.

Corresponding Author: Samantha A. Miner, DPM, Mount Auburn Hospital, 330 Mount Auburn St, Cambridge, MA 02138. (E-mail: dr.sam.miner@gmail.com) ment of complex patients and chronic diseases. ${ }^{1}$ One common example is the collaboration between vascular surgeons and podiatric surgeons in the treatment of chronic wounds. ${ }^{2,3}$ Furthermore, respecting and understanding roles has been identified as one of the ten principles of good interdisciplinary teamwork. ${ }^{4}$

In a previous survey of students currently attending Temple University School of Podiatric Medicine, Philadelphia, Pennsylvania, it was discovered that $64.9 \%$ were not made aware of podiatric medicine as a career option by their pre-health advisors while completing undergraduate coursework. Instead, it was reported that most podiatric medical students became interested in podiatric medicine either based on personal experiences as a podiatric patient or having a family member in the profession. ${ }^{5}$

From these preliminary data it can be inferred that undergraduate students interested in the 
health professions may not be adequately exposed to podiatric medicine's role in health care early on in their professional development. Furthermore, there is currently no scientific literature on the exposure of medical students (MSs) to the experiences and training of their podiatric counterparts. Although there have been various studies examining podiatric medical students' perspectives on their training and perceptions of the field, no studies regarding our allopathic and osteopathic colleagues' perceptions of podiatric medicine are present in the literature. . $^{6-10}$

As a result, the purpose of this study was to explore perceptions of podiatric education, training, and scope of practice from the perspective of MSs in the Philadelphia area through a self-reported, anonymous survey. We hypothesized that allopathic and osteopathic MSs in the Philadelphia area would show gaps in knowledge regarding the specialty field of podiatric medicine.

In addition, we expected that students from the Lewis Katz School of Medicine at Temple University (LKSOM) would be more likely than students from the other local medical schools to answer survey questions regarding their podiatric medicine counterparts correctly due to an association with one of the nine podiatric medical schools. It was also hypothesized that students with a parent/relative in the medical field, as well as those in higher stages of their medical school training (ie, in the third or fourth year of school) would answer a greater number of survey questions correctly. Although we chose to study a very specific population, it was our hope that this preliminary survey would demonstrate general areas of needed interprofessional education.

\section{Materials and Methods}

This cross-sectional survey study was approved by the institutional review board of Temple University.

\section{Survey Design}

Student leaders of the Student Chapter of the American College of Foot and Ankle Orthopedics and Medicine Club at Temple University School of Podiatric Medicine were consulted to aid in the development of survey questions. A list of questions was initially compiled with the help of these students based on what they expected their peers at osteopathic and allopathic medical schools to understand about podiatry as a medical specialty.
The list of survey questions was then narrowed to 16 questions by the authors for brevity and conciseness.

The final list of survey questions aimed to retrieve opinions with minimal bias regarding the field of podiatric medicine. The 16-question survey was divided into four sections, including respondent demographics (section I, questions 1-6), podiatric medical education and training (section II, questions 7-10), and podiatric scope of practice (section III, questions 11-16). Section IV, postsurvey education, was included to provide respondents with Web site links if they were interested in learning more about the field of podiatry. See Table 1 for the complete survey.

Most of the questions were quantitative (multiple choice, select all that apply, linear scale) in nature, with few qualitative (short answer) questions. Categorical scales were predominantly used for survey answer choices. Survey participants were asked to answer all questions to the best of their current knowledge. In addition, because the survey was meant to gauge student's perceptions and opinions, they were advised that there were no implicitly correct or incorrect answers. Participants were informed before beginning that consent was obtained by completing the electronic survey.

\section{Survey Distribution and Participants}

Medical students enrolled at the four allopathic medical schools and one osteopathic medical school in the Philadelphia area were invited to participate in this anonymous, self-reported survey study. For ease of distribution, the online Google Forms was chosen as the mode of survey delivery. A link to the survey was distributed to MSs via e-mail and/or posted in a closed Facebook group by a predetermined point of contact at each individual institution to reduce invasions of the students' privacy.

The survey was distributed to MSs at LKSOM, Perelman School of Medicine at the University of Pennsylvania (Penn Med), Sidney Kimmel Medical College at Jefferson Medical College (SKMC), and Philadelphia College of Osteopathic Medicine (PCOM). Attempts to distribute the survey to MSs at Drexel University's College of Medicine (DUCOM) were unsuccessful.

The recruitment period ran from September 1 to December 31, 2017. The link to the survey was resent to the students 1 month after the initial attempt using the original method of contact (ie, via e-mail and/or Facebook group) to encourage participation. Respondents were not able to edit their responses after submitting the survey. Students were limited to one 
Table 1. Self-reported Electronic Survey Outline with Total Responses

\begin{tabular}{|c|c|c|c|}
\hline Section & Question & Answer Choices & $\begin{array}{c}\text { Responses } \\
\text { (No. }[\%])(\mathrm{N}=129)\end{array}$ \\
\hline \multirow{42}{*}{$\begin{array}{l}\text { I. Respondent } \\
\text { demographics }\end{array}$} & \multirow[t]{5}{*}{ 1. What medical school do you attend? } & a. LKSOM & $37(28.7)$ \\
\hline & & b. Penn Med & $34(26.4)$ \\
\hline & & c. SKMC & $31(24.0)$ \\
\hline & & d. PCOM & $27(20.9)$ \\
\hline & & e. DUCOM & 0 \\
\hline & \multirow[t]{4}{*}{ 2. What year are you in your program? } & a. MS-1 & $51(39.5)$ \\
\hline & & b. MS-2 & $42(32.6)$ \\
\hline & & c. MS-3 & $19(14.7)$ \\
\hline & & d. MS-4 & $17(13.2)$ \\
\hline & \multirow{3}{*}{$\begin{array}{l}\text { 3. Do you have a parent(s) or close } \\
\text { relative(s) who is a physician? }\end{array}$} & a. Yes & $42(32.6)$ \\
\hline & & b. No & $87(67.4)$ \\
\hline & & c. I'm not sure & 0 \\
\hline & \multirow{19}{*}{$\begin{array}{l}\text { 4. If you answered "yes" to the previous } \\
\text { question, what specialty is/are he/she/ } \\
\text { they? } \\
\text { (short answer) }\end{array}$} & Internal medicine & $14(33.3)$ \\
\hline & & Cardiology & $4(9.5)$ \\
\hline & & Oncology & $4(9.5)$ \\
\hline & & Pediatrics & $4(9.5)$ \\
\hline & & Podiatry & $4(9.5)$ \\
\hline & & Surgery & $4(9.5)$ \\
\hline & & Emergency medicine & $3(7.1)$ \\
\hline & & Physical medicine and rehabilitation & $3(7.1)$ \\
\hline & & Psychiatry & $3(7.1)$ \\
\hline & & Radiology & $3(7.1)$ \\
\hline & & Anesthesiology & $2(4.8)$ \\
\hline & & Nephrology & $2(4.8)$ \\
\hline & & Obstetrics and gynecology & $2(4.8)$ \\
\hline & & Dermatology & $1(2.4)$ \\
\hline & & Endocrinology & $1(2.4)$ \\
\hline & & Infectious disease & $1(2.4)$ \\
\hline & & Orthopedics & $1(2.4)$ \\
\hline & & Pathology & $1(2.4)$ \\
\hline & & Other & $1(2.4)$ \\
\hline & \multirow{3}{*}{$\begin{array}{l}\text { 5. Have you ever heard of the field of } \\
\text { podiatric medicine? }\end{array}$} & a. Yes & $128(99.2)$ \\
\hline & & b. No & $1(0.8)$ \\
\hline & & c. I'm not sure & 0 \\
\hline & \multirow{8}{*}{$\begin{array}{l}\text { 6. If you answered "yes" to the previous } \\
\text { question, how have you heard about it? } \\
\text { (short answer) }\end{array}$} & $\begin{array}{l}\text { I have friends/family members/ } \\
\text { acquaintances in the field }\end{array}$ & $31(24.2)$ \\
\hline & & Personal experience as a patient & $30(23.4)$ \\
\hline & & $\begin{array}{l}\text { Personal experience working in a } \\
\text { health-care setting }\end{array}$ & $19(14.8)$ \\
\hline & & $\begin{array}{l}\text { Recruitment presentation, e-mails, } \\
\text { and/or ads }\end{array}$ & $15(11.7)$ \\
\hline & & It is common knowledge & $13(10.2)$ \\
\hline & & No response given & $10(7.8)$ \\
\hline & & I don't remember & $6(4.7)$ \\
\hline & & $\begin{array}{l}\text { Temple University's affiliation with } \\
\text { a podiatric medical school }\end{array}$ & $4(3.1)$ \\
\hline \multirow{6}{*}{$\begin{array}{l}\text { II. Podiatric medical } \\
\text { education and } \\
\text { training }\end{array}$} & \multirow{6}{*}{$\begin{array}{l}\text { 7. How many years of graduate professional } \\
\text { school does podiatry training require? }\end{array}$} & a. 0 & 0 \\
\hline & & b. 1 & 0 \\
\hline & & c. 2 & $7(5.4)$ \\
\hline & & d. 3 & $27(20.9)$ \\
\hline & & e. 4 & $62(48.1)$ \\
\hline & & f. I'm not sure & $33(25.6)$ \\
\hline
\end{tabular}


Table 1. continued

\begin{tabular}{|c|c|c|c|}
\hline Section & Question & Answer Choices & $\begin{array}{c}\text { Responses } \\
\text { (No. [\%]) }(\mathrm{N}=129)\end{array}$ \\
\hline \multirow{35}{*}{$\begin{array}{l}\text { III. Podiatric scope } \\
\text { of practice }\end{array}$} & \multirow{8}{*}{$\begin{array}{l}\text { 8. Which of the following basic medical } \\
\text { science subjects do podiatric medical } \\
\text { students take? (select all that apply) }\end{array}$} & a. Anatomy & $116(89.9)$ \\
\hline & & b. Physiology & $113(87.6)$ \\
\hline & & c. Pathology & $109(84.5)$ \\
\hline & & d. Pharmacology & $101(78.3)$ \\
\hline & & e. Internal medicine & $55(42.6)$ \\
\hline & & f. All of the above & $51(39.5)$ \\
\hline & & g. None of the above & $1(0.8)$ \\
\hline & & h. I'm not sure & $31(24.0)$ \\
\hline & \multirow{3}{*}{$\begin{array}{l}\text { 9. Do podiatric medical students take the } \\
\text { United States Medical Licensing } \\
\text { Examination? }\end{array}$} & a. Yes & $19(14.7)$ \\
\hline & & b. No & $59(45.7)$ \\
\hline & & c. I'm not sure & $51(39.5)$ \\
\hline & \multirow{3}{*}{$\begin{array}{l}\text { 10. Do podiatrists complete hospital-based } \\
\text { residencies? }\end{array}$} & a. Yes & $91(70.5)$ \\
\hline & & b. No & $5(3.9)$ \\
\hline & & c. I'm not sure & $33(25.6)$ \\
\hline & \multirow{3}{*}{$\begin{array}{l}\text { 11. When referring to a podiatrist is the term } \\
\text { "doctor" applicable? }\end{array}$} & a. Yes & $103(79.8)$ \\
\hline & & b. No & $16(12.4)$ \\
\hline & & c. I'm not sure & $10(7.8)$ \\
\hline & \multirow{3}{*}{$\begin{array}{l}\text { 12. Do podiatric physicians treat foot and } \\
\text { toenail fungus? }\end{array}$} & a. Yes & $114(88.4)$ \\
\hline & & b. No & $2(1.6)$ \\
\hline & & c. I'm not sure & $13(10.1)$ \\
\hline & \multirow[t]{3}{*}{ 13. Do podiatrists perform surgery? } & a. Yes & $102(79.1)$ \\
\hline & & b. No & $14(10.9)$ \\
\hline & & c. I'm not sure & $13(10.1)$ \\
\hline & \multirow{3}{*}{$\begin{array}{l}\text { 14. Are podiatric physicians involved in the } \\
\text { management of diabetes and its } \\
\text { complications? }\end{array}$} & a. Yes & $122(94.6)$ \\
\hline & & b. No & $3(2.3)$ \\
\hline & & c. I'm not sure & $4(3.1)$ \\
\hline & \multirow[t]{3}{*}{ 15. Do podiatrists prescribe medications? } & a. Yes & $105(81.4)$ \\
\hline & & b. No & $8(6.2)$ \\
\hline & & c. I'm not sure & $16(12.4)$ \\
\hline & \multirow{6}{*}{$\begin{array}{l}\text { 16. On a scale from } 0 \text { to } 5 \text {, how much of a } \\
\text { role do podiatrists generally play in } \\
\text { health care? ( } 0=\text { inessential; } 5= \\
\text { equivalent to MDs/DOs) }\end{array}$} & a. 0 & 0 \\
\hline & & b. 1 & $6(4.7)$ \\
\hline & & c. 2 & $24(18.6)$ \\
\hline & & d. 3 & $33(25.6)$ \\
\hline & & e. 4 & $40(31.0)$ \\
\hline & & f. 5 & $26(20.2)$ \\
\hline $\begin{array}{l}\text { IV. Postsurvey } \\
\text { education }\end{array}$ & \multicolumn{3}{|c|}{$\begin{array}{l}\text { You have completed the survey. Thank you for your participation! If you would like information } \\
\text { concerning the field of podiatric medicine, and our training, please see the links below. } \\
\text { - American Association of Colleges of Podiatric Medicine (http://www.aacpm.org) } \\
\text { - American Podiatric Medical Association (http://www.apma.org) } \\
\text { - American College of Foot and Ankle Surgeons (http://www.afcas.org) }\end{array}$} \\
\hline
\end{tabular}

Abbreviations: DUCOM, Drexel University's College of Medicine; LKSOM, Lewis Katz School of Medicine at Temple University; PCOM, Philadelphia College of Osteopathic Medicine; Penn Med, Perelman School of Medicine at the University of Pennsylvania; SKMC, Sidney Kimmel Medical College at Jefferson Medical College.

response by being required to sign into their Google account to complete the survey. No incentive was offered to the MSs for participating.

\section{Data Analysis}

The percentage of respondents was calculated for each survey question using Microsoft Excel (Microsoft Corp, Redmond, Washington). Inferences and conclusions were then drawn from the percentages of respondents.

Three subgroups were determined to better answer the hypotheses: the medical school of attendance, the year of study, and if a respondent had a physician relative. Subgroup analyses were performed with JMP Pro statistical software (SAS Institute Inc, Cary, North Carolina) using the Pearson $\chi^{2}$ test for demographic data and the Fisher 
Table 2. Summary of Statistical Significance for Survey Questions by Subgroup

\begin{tabular}{lcccc}
\hline \multirow{2}{*}{ Section } & & \multicolumn{3}{c}{$P$ Value } \\
\cline { 2 - 5 } & $\begin{array}{c}\text { Question } \\
\text { No. }\end{array}$ & $\begin{array}{c}\text { School of } \\
\text { Attendance }\end{array}$ & $\begin{array}{c}\text { Year of } \\
\text { Study }\end{array}$ & $\begin{array}{c}\text { Physician } \\
\text { Relative }\end{array}$ \\
\hline II (Training) & 7 & NC & NC & .0223 \\
& 8 & NC & NC & NC \\
& 9 & NS & NS & NS \\
III (Scope) & 10 & NS & NS & NS \\
& 11 & NS & NS & NS \\
& 12 & NS & NS & .0109 \\
& 13 & NS & NS & NS \\
& 14 & NS & NS & .0082 \\
& 15 & .0185 & NS & NS \\
& 16 & NC & NC & .0248
\end{tabular}

Abbreviations: NC, not calculated (for all survey questions due to the size of the contingency table or the nature of the question); NS, not significant.

exact test for the remaining individual questions. Due to the small sample size and possible presence of " 0 " responses for some question parameters, the Fisher exact test for independence was chosen over the $\chi^{2}$ test for analysis of most of the survey data. Statistical significance was defined at $P<.05$. See Table 2 for a summary of statistical significance for survey questions by subgroup.

Due to the size of contingency tables, Fisher exact tests were not able to be calculated for questions 7 and 16 for the school of attendance and year of study subgroups. Question 8 was excluded from the analysis for independence due to the nature of the question (ie, select all that apply). In addition, the median of the total responses, as well as within each subgroup, was calculated for question 16 and is presented in Table 4.
Table 3. Subgroup Analysis for Survey Question 16 Demonstrating the Calculated Median Response

\begin{tabular}{lc}
\hline Subgroup & Median \\
\hline Total respondents & 4 \\
Medical school & \\
LKSOM & 3 \\
Penn Med & 4 \\
SKCM & 4 \\
PCOM & 4 \\
Year of study & \\
MS-1 & 3 \\
MS-2 & 4 \\
MS-3 & 4 \\
MS-4 & 3 \\
Physician relative & \\
Yes & 4 \\
No & 3 \\
\hline
\end{tabular}

Abbreviations: LKSOM, Lewis Katz School of Medicine at Temple University; PCOM, Philadelphia College of Osteopathic Medicine; Penn Med, Perelman School of Medicine at the University of Pennsylvania; SKMC, Sidney Kimmel Medical College at Jefferson Medical College.

\section{Results}

Approximately 4,500 MSs at one osteopathic and three allopathic medical schools were surveyed regarding their perceived impressions of the podiatric medicine profession. A total of 129 responses were obtained after two survey distribution attempts at each of the four schools, for an overall response rate of approximately $2.9 \%$. A list of the survey questions by section is presented in Table 1 , along with the response rate for each answer choice.

\section{Study Population Characteristics}

The first section of the survey collected data regarding demographic characteristics of the study

Table 4. Demographic Data of Survey Participants

\begin{tabular}{|c|c|c|c|c|c|c|c|}
\hline Medical School & $\begin{array}{c}\text { Total } \\
(\mathrm{N}=129)\end{array}$ & $\begin{array}{l}\text { Physician } \\
\text { Relative } \\
(n=42)\end{array}$ & $\begin{array}{c}\text { No Physician } \\
\text { Relative } \\
(\mathrm{n}=87)\end{array}$ & $\begin{array}{c}\text { MS-1 } \\
(n=51)\end{array}$ & $\begin{array}{c}\text { MS-2 } \\
(n=42)\end{array}$ & $\begin{array}{c}\text { MS-3 } \\
(n=19)\end{array}$ & $\begin{array}{c}\text { MS-4 } \\
(n=17)\end{array}$ \\
\hline LKSOM & 37 (28.7) & 10 & 27 & 16 & 11 & 4 & 6 \\
\hline Penn Med & $34(26.4)$ & 13 & 21 & 9 & 8 & 8 & 9 \\
\hline SKMC & $31(24.0)$ & 11 & 20 & 20 & 6 & 4 & 1 \\
\hline PCOM & $27(20.9)$ & 8 & 19 & 6 & 17 & 3 & 1 \\
\hline DUCOM & 0 & 0 & 0 & 0 & 0 & 0 & 0 \\
\hline
\end{tabular}

Note: Data are given as number (\%).

Abbreviations: DUCOM, Drexel University's College of Medicine; LKSOM, Lewis Katz School of Medicine at Temple University; PCOM, Philadelphia College of Osteopathic Medicine; Penn Med, Perelman School of Medicine at the University of Pennsylvania; SKMC, Sidney Kimmel Medical College at Jefferson Medical College. 
population. Table 4 summarizes this information. We included questions concerning medical school of attendance (eg, LKSOM, Penn Med, SKCM, or PCOM) and year of study (eg, MS-1, MS-2, MS-3, or MS-4). The distribution of respondents from each school was relatively uniform, with LKSOM having the greatest number of respondents $(28.7 \%, \mathrm{n}=37)$ and PCOM having the fewest $(20.9 \%, \mathrm{n}=27)$. The number of respondents in each year of study was less evenly distributed. First-year and second-year MSs made up almost two-thirds of the study population (MS-1: 39.5\%, $\mathrm{n}=51$; MS-2: $32.6 \%, \mathrm{n}=$ 42). A $\chi^{2}$ test comparing school of attendance and year of study revealed a significant result $(P=.0004)$ with a $\chi^{2}$ statistic of 30.2757 .

In addition, we found that $32.6 \%$ of respondents (n $=42$ ) had at least one parent or close relative who is a physician (Table 4), with the most commonly reported specialty being internal/family medicine $(33.3 \%, \mathrm{n}=14)$. Interestingly, podiatric medicine was one of the more commonly reported specialties, with four students (9.5\%) having a family member in the field. A full list of the reported specialties can be found in Table 1, question 4. The association between having a physician relative and medical school of attendance did not show significance $\left(\chi^{2}=\right.$ 1.0998, $P=.7771$ ), suggesting that the population was uniformly distributed regarding students with physician relatives at each participating school.

When asked if they had heard of the field of podiatric medicine, all but one MS responded "yes" $(99.2 \%, \mathrm{n}=128)$. Students reported most commonly that they had heard of podiatry through friends, family, and/or acquaintances in the profession $(24.2 \%, \mathrm{n}=31)$ or through personal experience as a patient of a podiatrist $(23.4 \%, \mathrm{n}=30)$.

\section{Podiatric Medical Training}

The second section of the survey revealed that less than half of the MSs surveyed perceived that podiatric medical school is 4 years in length $(48.1 \%, \mathrm{n}=62)$, and $25.6 \%(\mathrm{n}=33)$ were not sure how many years of schooling is required (Table 1, question 7). Students who stated that they have a physician relative were greater than two times more likely to respond "I'm not sure" than students who stated that they do not have a physician relative (Fig. 1). The Fisher exact test for independence yielded a $P=.0223$, which implies that the difference in responses to this question based on the two populations of physician relative and no physician relative was statistically significant.
Most MSs responded that they believe their podiatric counterparts take basic medical science courses in anatomy $(89.9 \%, \mathrm{n}=116)$, physiology (87.6\%, $\mathrm{n}=113)$, pathology $(84.5 \%, \mathrm{n}=109)$, and pharmacology $(78.3 \%, \mathrm{n}=101)$. However, they were least likely to select internal medicine in the list of courses presented in question $8(42.6 \%, \mathrm{n}=55)$. Even fewer students correctly selected all courses from the list (39.5\%, $\mathrm{n}=51$ ) (Table 1, question 8).

Survey question 9 asked MSs if their podiatric counterparts take the same board examination, the United States Medical Licensing Examination, as they do. The response was mixed, with $45.7 \%$ ( $\mathrm{n}=$ $59)$ of students answering "no" and 39.5\% ( $\mathrm{n}=51)$ answering "I'm not sure." Regarding whether podiatric physicians complete a hospital-based residency, most of the survey participants believed that they indeed do $(70.5 \%, \mathrm{n}=91)$; however, just more than $25 \%$ were not sure $(25.6 \%, \mathrm{n}=33$ ) (Table 1 , question 10).

Subgroup analysis regarding medical school of attendance and year of study did not yield any statistically significant differences for questions 7 through 10 in section II. As previously discussed, one question in this section (question 7) showed statistical significance with the Fisher exact test regarding the physician relative subgroup (Table 2).

\section{Podiatric Scope of Practice}

In section III of the survey, we found that MSs responded relatively positively to questions 11 to 15 , with an average $85 \%$ response rate of "yes" to questions regarding the inclusion of matters in the podiatric scope of practice. Regarding survey question 11 , just less than $80 \%$ of total respondents answered that they would consider a podiatrist to be a doctor, a few said that they would not (12.4\%, $\mathrm{n}$ $=16)$, and even fewer were not sure $(7.8 \%, \mathrm{n}=10)$ (Table 1).

Although the total response rate indicating "yes" for the questions in this section was high, students were more willing to answer that podiatric physicians treat toenail fungus (question 12: $88.4 \%, \mathrm{n}=$ 114 ) and manage complications of diabetes (question 14: $94.6 \%, \mathrm{n}=122$ ) than perform surgery (question 13: $79.1 \%, \mathrm{n}=102$ ) or prescribe medications (question 15: 81.4\%, $\mathrm{n}=105$ ) (Table 1).

Subgroup analysis for questions 11 through 15 did not reveal statistical significance regarding year of study. The school of attendance subgroup similarly did not demonstrate a statistically significant difference between the subpopulations in this section, except for question 15 regarding the 


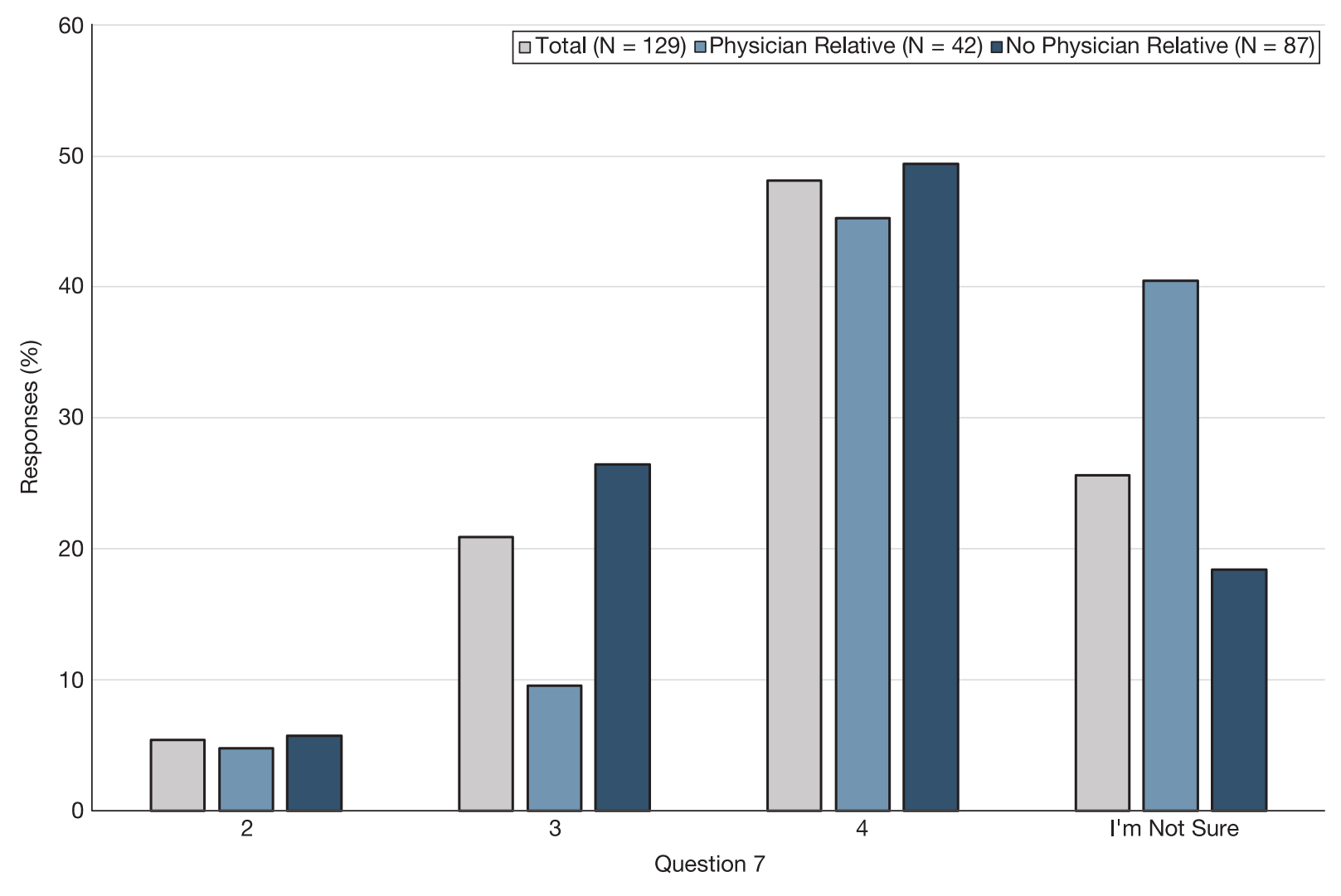

Figure 1. Summary of total responses and responses from the physician relative subgroup to survey question 7 regarding length of podiatric medical school. A significant difference between the physician relative and no physician relative subpopulations was found $(P=.0223)$.

prescription of medications by podiatrists $(P=$ .0185) (Table 2).

The physician relative subgroup revealed significance for multiple survey questions in section III, including question $12(P=.0109)$ and question $14(P$ $=.0082$ ), as well as question 16 (Table 2). The common trend in the difference in response rate between these two populations for questions 12 and 14 seems to be a greater willingness of respondents without a physician relative to answer "yes" to these questions than those with a physician relative. Respondents with a physician relative were also more likely than those without to respond "I'm not sure" for these two questions (Fig. 2).

The last survey question, question 16, asked MSs to rate podiatric medicine's general role in health care on a scale from 0 (inessential) to 5 (equivalent to $\mathrm{MDs} / \mathrm{DOs}$ ). The response was generally positive, with most of the students responding with a rating of either 3 or 4 on the scale. The median for all 129 respondents was 4 . Table 3 summarizes the calculated median for each subgroup. The calculated median response was 4 for all schools, except for LKSOM, which was calculated to be 3 . Students in years 1 and 4 had a calculated median of 3 , and students in years 2 and 3 had a median of 4 . Respondents with a physician relative were more likely to give a higher rating on the scale than those without a physician relative, as evidenced by their higher median rating and the associated significant difference between the two groups $(P=.0248)$ (Table 2).

\section{Discussion}

The aim of this study was to gauge perceptions of MSs regarding the specialty field of podiatric medicine. We surveyed 129 MSs from one osteopathic and three allopathic medical schools in the Philadelphia area. The distribution of respondents from each of the four medical schools surveyed was generally uniform. Respondents from the first and second year of medical school composed approximately $72 \%$ of the survey population, and a 


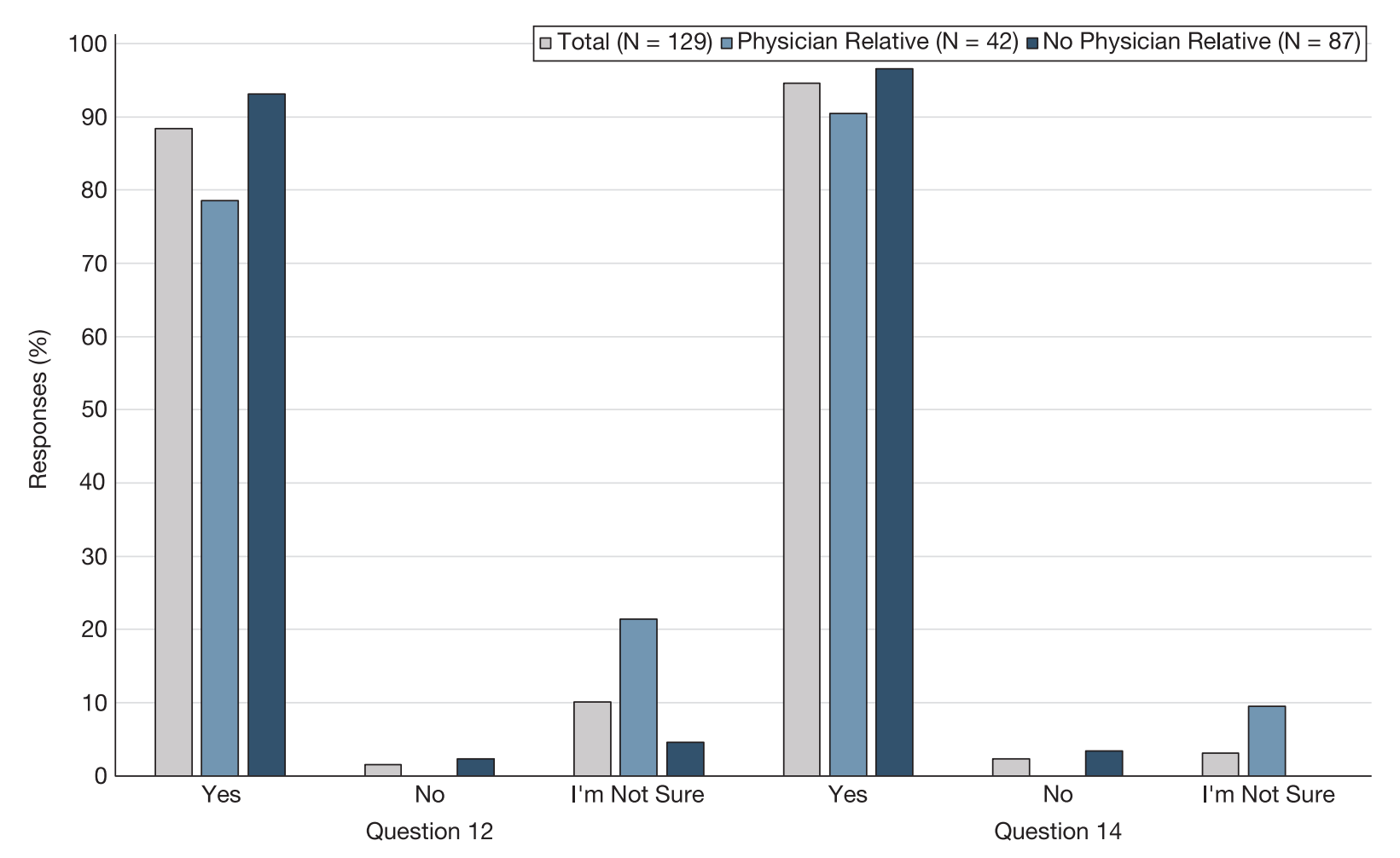

Figure 2. Percentage responses for survey questions 12 and 14 with the physician relative subgroup represented regarding scope of podiatric medical practice. Significant differences between the physician relative and no physician relative subpopulations were found for question $12(P=.0109)$ and question $14(P=$ .0082).

significant difference was seen between school of attendance and year of study $(P=.0004)$. Although we had hoped to survey students from DUCOM to increase the total number of respondents, as well as to have a representative MS population from the Philadelphia area, they were deemed inaccessible after multiple failed attempts at survey distribution.

As previously stated, a survey of podiatric medical students demonstrated that most had become interested in podiatric medicine either through personal experiences from being treated by a podiatric physician or having a family member in the profession. ${ }^{5}$ Similarly, this was the case for the present survey population of MSs, with $23.4 \%$ (n $=30$ ) having been treated by a podiatric physician in the past and $24.2 \%(\mathrm{n}=31)$ having one or more friends or family members in the profession (question 6). The fourth most common reason identified by MSs as being responsible for exposing them to podiatric medicine was recruitment presentations, e-mails, and advertisements $(11.7 \%, \mathrm{n}=$ 15). Also, four respondents mentioned Temple University's affiliation with a podiatric medical school specifically as to how they had learned about it.

We hypothesized that allopathic and osteopathic medical students would show gaps in knowledge with respect to podiatric medical education, training, and scope of practice. In general, we found that MSs were either well informed or good at guessing the perceived "correct" answer regarding our 16question, self-reported survey. For instance, all but one respondent had previously heard of the field of podiatric medicine (question 5), and approximately $80 \%$ would agree that the term doctor is applicable to a podiatrist (question 11).

However, there were survey questions that identified areas of needed interprofessional education. Specifically, there seemed to be confusion among MSs regarding the length of podiatric medical school (question 7), with less than half of the respondents choosing the real-world correct answer of 4 years. In addition, only $42.6 \%$ of respondents chose internal medicine from a list of basic medical science courses that they believed podiatric medical students take during their training 
(question 8), despite it being a standard course of the podiatric medicine curriculum. ${ }^{11}$

Furthermore, less than half of respondents were aware that podiatric medical students do not take the same board examinations as MSs, with a relatively large percentage (39.5\%) reporting that they were unsure (question 9). It was also apparent that regarding podiatric medicine's scope of practice, MSs were more likely to report that podiatrists treat toenail fungus (question 12) and manage complications of diabetes (question 14) than perform surgery (question 13) or prescribe medications (question 15). In addition, only $20.2 \%$ of respondents rated podiatrists as having a role in health care equivalent to allopathic and osteopathic physicians (question 16, represented by 5 on the scale). Most of the MSs were more likely to rate podiatric medicine's role as a $4(31.0 \%, \mathrm{n}=40)$ or a $3(25.6 \%, \mathrm{n}=33)$ on this scale, with a median of 4 . This is generally a positive result because we can see that most MSs believe that podiatry's role is not inessential (represented by 0 on the scale) and instead approaches the role of other physicians in the health-care system.

We hypothesized that students from the LKSOM at Temple University would be more likely than students from other medical schools to answer survey questions regarding their podiatric medical counterparts correctly due to an affiliation with one of the nine podiatric medical schools. However, school of attendance subgroup analysis did not reveal a statistically significant result for most of the questions, with one exception (question 15). This implies that there was no statistically significant difference in the response to most survey questions based on school of attendance and that the hypothesis was, therefore, incorrect. Interestingly, LKSOM had the lowest median score of any school surveyed for question 16 regarding the role that podiatrists play in health care. Because a lower score on the scale represents a more minor role, it could be interpreted that students at LKSOM are more negatively biased toward podiatric physicians than the other schools surveyed. However, this may just be a coincidence of the data due to the small sample size.

Similarly, we expected that those in higher stages of their medical school training (ie, in their third or fourth year of school) would answer more survey questions correctly because they may have more clinical exposure to podiatry through hospital rotations. Contrary to the hypothesis, we found no statistically significant difference between responses when comparing students' year of study.
We also hypothesized that MSs with a parent or close relative in the medical field would perform better on the survey than those who did not because they may have been exposed to medicine and its specialties through relative connections and/or experiences that those without a physician parent or relative did not have. Analysis of the physician relative subpopulation found that MSs with a physician relative were more likely to be unsure of their answer for multiple survey questions, which was determined to be statistically significant compared with the population without a physician relative. However, when scoring the role that podiatric medicine plays in health care, those with a physician relative were more likely to give a higher score (median $=4$ ) than those without a physician relative (median $=3$ ).

This survey study had many limitations. One of the most significant limitations was the study's small sample size. To minimize invasion of privacy, the survey link was distributed to MSs by a point of contact at each school that was predetermined by the investigators. We believe that this indirect form of contact with the study population, as well as the lack of incentive provided to participants, resulted in the small sample size of 129 respondents. As a result, the study is subject to population bias. The percentage of MSs who completed the survey is a small proportion of the total number of medical students who were asked to participate (2.9\%). Furthermore, it is possible that MSs with previous knowledge of podiatry were more likely to participate in the study, which could have skewed the results in a more positive light. Therefore, the results may not be representative of the overall chosen population of study.

Another major limitation of this study is location bias. The results may be skewed toward positive responses regarding podiatric medicine because we surveyed MSs in a large city (Philadelphia) where podiatry is a thriving specialty, and where one of the nine podiatric medical schools in the United States is located. It is unknown whether this same survey would obtain similar results in a less urban area, where podiatric medicine may not have as significant of a presence, or in the general MS population countrywide.

Although $72 \%$ of survey respondents were firstand second-year MSs, the results demonstrated no statistically significant difference between survey question responses by year of study. This finding is concerning, especially when considered with the result that only $14.8 \%$ of respondents stated that they had exposure to podiatric medicine through 
personal experience working in the health-care setting (question 6). Despite the limitations of this study, the findings may suggest that it is necessary to provide MSs with podiatry-specific education through interdisciplinary workshops before entering the medical community as physicians to prevent misunderstandings and provide the highest quality care.

Due to a lack of literature regarding the perceptions of podiatric medicine from those outside the field, and the areas of needed interprofessional education that were identified in this preliminary study, additional studies are needed to further evaluate this topic. It may also be necessary to assess perceptions of podiatry from the perspective of other members of the health-care team to improve interprofessional relations and understanding of podiatric medicine's place in medicine.

\section{Conclusions}

The results of this survey help to elucidate the perceptions of the podiatric medicine profession according to MSs in the Philadelphia area. Although misconceptions were identified regarding podiatric education and scope of practice, the perceptions regarding the role of a podiatrist in the health-care system were generally positive and optimistic. Although we chose to study a very specific population of MSs, it was our hope that this preliminary survey would demonstrate general areas of needed education to foster interdisciplinary understanding of podiatric medicine.

Acknowledgment: John Martucci, Daniel Wu, and Scott Hudzinski for their contributions to this study. Financial Disclosure: None reported.
Conflict of Interest: None reported.

\section{References}

1. Mulvale G, Embrett M, Razavi SD: "Gearing Up" to improve interprofessional collaboration in primary care: a systematic review and conceptual framework. BMC Fam Pract 17: 83, 2016.

2. Wu T, Chaer RA, Salvo NL: Building effective partnerships between vascular surgeons and podiatric physicians in the effective management of diabetic foot ulcers. JAPMA 106: 308, 2016.

3. SANDERs LJ, Robins JM, Edmonds ME: History of the team approach to amputation prevention: pioneers and milestones. J Vasc Surg 52: 3S, 2010.

4. Nancarrow SA, Booth A, Ariss S, et aL: Ten principles of good interdisciplinary team work. Hum Resour Health 11: 19, 2013.

5. Pennsylvania Podiatric Medical Association: TUSPM students conduct survey to pinpoint decline in enrollment. PPMA Update (June/July): 1, 2016.

6. Bertram K, Randazzo J, Alabi N, ET AL: Strong correlations between empathy, emotional intelligence, and personality traits among podiatric medical students: a crosssectional study. Educ Health 29: 186, 2016.

7. Chumbler NR, RobBins JM: Podiatric medical students' views toward geriatrics and elderly patients: a preliminary study. JAPMA 84: 338, 1994.

8. Chumbler NR, Robbins JM, Poplawksi ME: Rewards of entering podiatric medicine and attitudes toward older adults. JAPMA 86: 288, 1996.

9. Parsley NL, Harris IB: Podiatric medical students' perceptions of professionalism in the clinical setting: a qualitative analysis. JAPMA 102: 434, 2012.

10. SHofler DW, Bosia K, Harkless L. Fourth-year podiatric medical student perspectives on clerkships and residency selection. JAPMA 108: 311, 2018.

11. AACPM Council of FAculties. Curricular guide for podiatric medical education, 2017 edition. Available at: https://www.aacpm.org/wp-content/uploads /2017AACPMCurricularGuide.pdf. 